\title{
Imagine Yourself a Physicist
}

\author{
Educators and other professionals seeking to increase participation of \\ underrepresented communities in science can learn from online methods \\ that help youths visualize themselves in STEM careers.
}

\author{
By Darron Lamkin and Tutaleni I. Asino
}

magine that you had never met a physicist, had never heard of the profession, and had never been taught what

a physicist does. How likely do you think it is that you would have grown up to be a physicist? While every young person deserves the opportunity to pursue a career that offers the possibility of a brighter future, some futures are not universally accessible. In many impoverished communities, jobs are mostly available in loan companies, in restaurants, and in liquor and other convenience stores. Youth have minimal exposure to other opportunities and, as a result, do not see themselves in science, technology, engineering, and math (STEM) careers. To combat this lack of exposure, we need intervention programs that can close the opportunity gap in STEM education.

The question "What do you want to be when you grow up?" requires a young person to imagine themselves in the distant future. This projection is referred to as the "Possible Selves

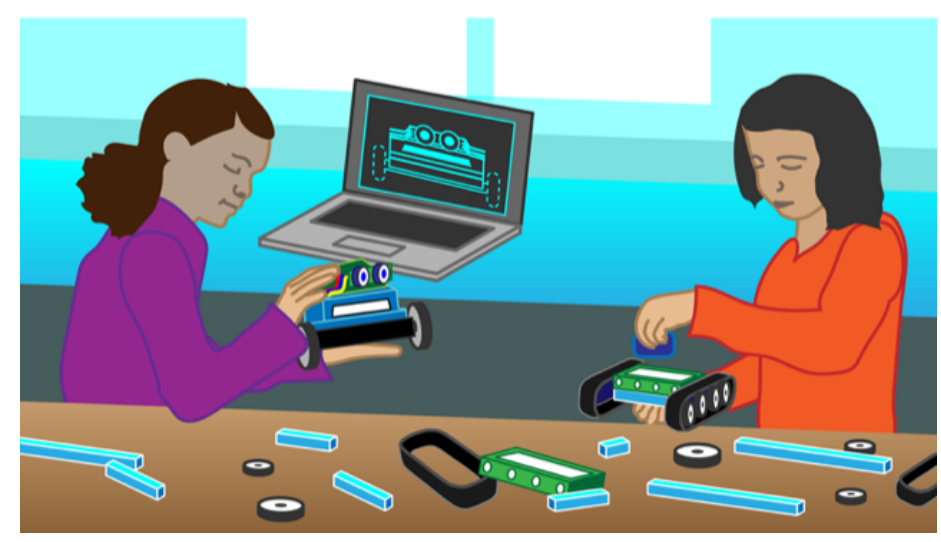

Students work with mentors to design and make mini robots at home via the Class Matters online platform.

Credit: APS/Alan Stonebraker
Theory." Possible selves, as defined by psychologists, represent individuals' ideas of what they could become, what they would like to become, and what they fear becoming, and thus they provide a conceptual link between cognition and motivation. The theory provides a framework for developing out-of-school programs that expose students to STEM and that allow them to envision themselves in related careers. Exposure can include workshops, classroom visits by experts, after-school camps, and even simply seeing STEM professionals who "look like them."

Many out-of-school STEM programs provide technical instruction as well as family, peer, and community support. For example, First Robotics engages kindergarten through high-school kids in mentor-based research and robotics programs. Another, Project Lead The Way, creates age-appropriate, hands-on programs in computer science, engineering, and biomedical science for classroom environments with the aim of helping students develop in-demand STEM knowledge and skills. However, few of these programs engage socially and economically disadvantaged youth, who tend to be underrepresented in STEM. We need programs that are carefully tailored for these young people and that expose them to the possibility of being scientists.

We have created one such intervention program, called Class Matters. This program serves youth who face academic and behavioral challenges in Oklahoma City. By engaging with rural and inner-urban high-school students and first-year college students, the program seeks to improve high-school graduation rates, college enrollment rates, and professional development after graduation. Class Matters provides in-person and virtual programs that teach STEM concepts using everyday household items, including items found in the recycling bin. The participants foster the thinking skills-identifying problems, 


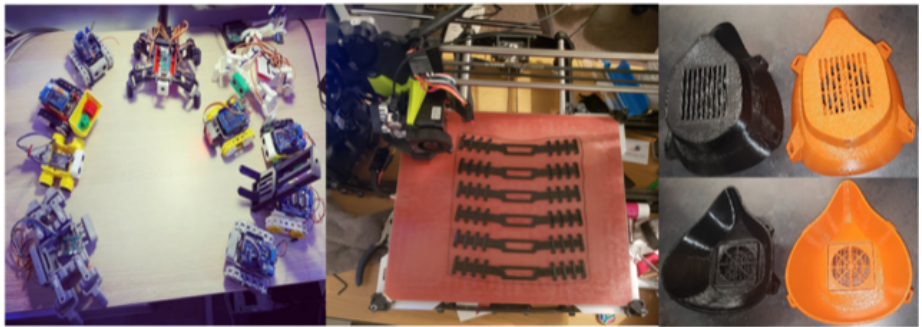

Students learn about STEM by using materials they have at home to design and make mini robots, ear protectors for surgical masks, and 3D-printed masks.

Credit: D. Lamkin/Class Matters Inc.

analyzing information, and drawing conclusions from evidence-that are necessary to successfully pursue physics, engineering, and other scientific careers.

In more detail, participants in Class Matters learn how to problem solve, to express themselves creatively, to resolve conflicts amicably, and to collaborate with their peers on projects, all while they gain STEM skills, such as coding, programming, circuit designing, and robot making. Volunteer mentors, who are engineers, scientists, and teachers in all areas of STEM, guide students through prepared activities that are tailored to their age. Using reverse engineering and engineering design processes, for example, teenagers develop and create 3D printed masks, ear protection for surgical mask wearers, and mini robots that are programmed to perform a mechanical function (movement) and a display function (flashing lights).

Ten years after its founding, Class Matters has served more than 40 cohorts, each averaging 30 to 45 students. Of Class Matters alumni, $94 \%$ have enrolled in STEM-related studies and $84 \%$ are working as either STEM professionals or educators. In addition, $60 \%$ of Class Matters alumni remain local and have an income range of between $\$ 45,000$ to $\$ 125,000$, and many alumni also mentor new Class Matters participants in their community. Finally, alumni take part in community-based initiatives to reduce crime and poverty. By providing alternatives and distractions to destructive choices, such as gang participation and drug use, extracurricular and educational programs can help to reduce crime and delinquent behavior. By helping more young people to focus on their own education and future, Class Matters has helped create a positive feedback loop that enables students to make positive contributions to their communities.

Exposing students to STEM career options does not magically transform their futures. However, a young person's response to "what do you want to be when you grow up?" depends on his or her vocabulary and the options to which he or she has been exposed. We all have a story of how we were exposed to a specific path that guided our professional choices. For example, a physics teacher who explained Newton's laws of motion in an unforgettable way and created a spark that is now a flame and is being nurtured as a career. Without that exposure, the possible selves that we can envision are severely limited. A multitude of challenges and systemic issues prevent certain populations from excelling at STEM careers. Exposing underrepresented youth to STEM careers must be part of the solution.

Darron Lamkin: Oklahoma State University, Stillwater, OK, USA

Tutaleni I. Asino: Oklahoma State University, Stillwater, OK, USA 